\title{
Anterior Temporal Lobectomy Impairs Neural Classification of Body Emotions in Right Superior Temporal Sulcus and Reduces Emotional Enhancement in Distributed Brain Areas without Affecting Behavioral Classification
}

\author{
Laura Van de Vliet, ${ }^{1}$ Jan Jastorff, ${ }^{1}$ Yun-An Huang, ${ }^{1}$ CWim Van Paesschen, ${ }^{2}$ Mathieu Vandenbulcke, ${ }^{1,3}$ \\ and Jan Van den Stock ${ }^{1,3,4}$ \\ ${ }^{1}$ Laboratory for Translational Neuropsychiatry, Research Group Psychiatry, Department of Neurosciences, KU Leuven, Leuven 3000, Belgium, ${ }^{2}$ Department \\ of Neurology, Laboratory for Epilepsy Research, University Hospitals and KU Leuven, Leuven 3000, Belgium, ${ }^{3}$ Geriatric Psychiatry, University Hospitals

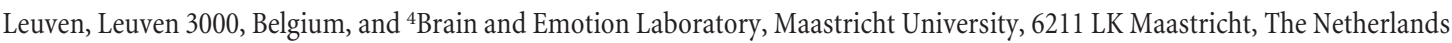

Humans with amygdalar lesions show proportional reductions of the emotional response to facial expressions in the fusiform face area as well as deficits in emotion recognition from facial expressions. While processing of bodily expressions shares many similarities with facial expressions, there is no substantial evidence that lesions of the amygdala result in similar behavioral and neural sequelae. We combined behavioral assessment with functional neuroimaging in a group of male and female humans with unilateral anterior temporal lobe (ATL) resections, including the amygdala (right: $n=10$; left: $n=10$ ) and 12 matched controls. The objective was to assess whether the amygdala is crucial for the recognition of body expressions and for modulatory effects on distant areas during perception of body expressions. The behavioral results revealed normal performance in both patient groups on emotion categorization of body expressions. The neuroimaging results showed that ATL patients displayed no enhanced activations in right fusiform body area and left extrastriate body area and that left ATL patients additionally displayed no enhanced activations in right posterior superior temporal sulcus and right extrastriate body area, respectively. Multivoxel pattern analysis revealed altered categorization capacity between emotional and neutral stimuli in right posterior superior temporal sulcus in right ATL patients. In addition, we also found emotional enhancement in frontal, parietal, occipital, and cingulate regions in controls. Together, our data show that the amygdala and ATLs are not necessary for recognition of dynamic body expressions, but suggest that amygdala lesions affect body emotion processing in distant brain areas.

Key words: amygdala; body; connectivity; emotion; lobectomy; MVPA

Significance Statement

For humans, information from emotional expressions of others is crucial to support social interactions. The majority of emotion studies has focused on facial expressions; however, in daily life, we also use information from body postures and body movement. Visual processing of body expressions relies on a brain network, including body-specific visual areas and visuomotor areas. Even though the importance of the amygdala and its modulatory effects on distant brain regions have been documented, it remains unclear whether the amygdala plays a crucial role in emotional body processing. By combining behavioral and neuroimaging data in patients with amygdalar lesions, we provide further evidence for its modulatory effect on distant areas during the perception of body expressions.

\section{Introduction}

Converging evidence from functional imaging studies and neuropsychological studies in clinical cohorts indicate that the ante- rior temporal lobe (ATL) and the amygdala in particular are key components of the "emotional brain" (Adolphs et al., 1994; Mor-

L.V.d.V. was supported by Fonds Wetenschappelijk Onderzoek-Vlaanderen aspirant fellowship grant $11 Z 8917$ N. J.J. is a postdoctoral researcher supported by Fonds Wetenschappelijk Onderzoek-Vlaanderen. J.V.d.S was supported by Fonds Wetenschappelijk Onderzoek-Vlaanderen and a KU Leuven starting grant. We thank all patients and healthy volunteers for cooperation; Dr. Kristof Vansteelandt for advice on statistics; and Jochen Weber for technical support. 
ris et al., 1996; Olson et al., 2007; Fusar-Poli et al., 2009; Adolphs, 2010; Haxby and Gobbini, 2011; Bickart et al., 2014). The role of the amygdala in emotional face processing has been well established by means of functional imaging (Vuilleumier and Pourtois, 2007) and lesion studies. Patients with bilateral amygdalar lesions show impaired recognition of facial expression, particularly fear, and this deficit appears more pronounced compared with unilateral lesions (Adolphs et al., 1994, 1999). Also, neurodegenerative disorders characterized by amygdala atrophy, such as behavioral variant frontotemporal dementia (bvFTD), are associated with deficits in facial expression recognition, and this deficit is proportional to amygdalar volume (Rosen et al., 2002; De Winter et al., 2016; Kumfor et al., 2017). Unilateral anterior temporal lobectomy typically includes the amygdala and results in facial emotion recognition impairments (Adolphs et al., 1994; Monti and Meletti, 2015). Amygdalar modulatory effects at distance, especially in face-selective areas, further corroborate the central role of the amygdala in the brain's response to emotional faces. Activity in amygdala correlates with activity in FFA during perception of facial expressions (Morris et al., 1998; Herrington et al., 2011; Diano et al., 2017), and fMRI studies in patients with both unilateral and bilateral amygdalar lesions show reductions of emotion effects in fusiform face area proportional to the lesion extent (Vuilleumier et al., 2004; De Winter et al., 2016), supporting the notion of a functional coupling between amygdala and fusiform face area. Recent work on bodily expressions seems to confirm the importance of this region in the processing of emotional body actions as well (Hadjikhani and de Gelder, 2003; de Gelder et al., 2004; de Gelder, 2006; Peelen et al., 2007; Pichon et al., 2008; Goldberg et al., 2015; Van den Stock, Hortensius, et al., 2015). Amygdala responses to body expressions correlate with responses in fusiform body area (FBA) and extrastriate body area (EBA) (Peelen et al., 2007). Furthermore, the amygdala, as a node in the emotion network, has strong connections with the action observation network and functions primarily as a source region (i.e., it modulates activation in other regions) (Jastorff et al., 2015; Huang et al., 2018). However, there is currently no evidence that the amygdala is directly involved in decoding or representing emotion-specific information independent of the mode of expression (e.g., Peelen et al., 2010; Skerry and Saxe, 2014) or correlations with emotion-recognition performance (Jastorff et al., 2015), although this may be related to multivariate pattern analysis (MVPA) limitations (Skerry and Saxe, 2014).

Activation patterns in other regions of the emotion or action observation network, such as the posterior STS (pSTS), reliably discriminate emotional expressions in body postures and other modalities (Peelen et al., 2010; Skerry and Saxe, 2014; Jastorff et al., 2015).

At the behavioral level, there is currently no strong evidence that lesions of the amygdala result in body expression recognition deficits (Atkinson et al., 2007; de Gelder et al., 2014). To study the role of the amygdala in bodily emotion recognition and its modulatory effect on distant areas during the perception of body expressions, we performed a series of behavioral and neuroimaging experiments in patients with unilateral ATL resections and matched controls. The aims of the study were as follows: (1) to

The authors declare no competing financial interests.

Correspondence should be addressed to Dr. Jan Van den Stock, Laboratory for Translational Neuropsychiatry, Department of Neurosciences, KU Leuven, 0\&N 2, bus 1027, Herestraat 49, 3000 Leuven, Belgium. E-mail: jan.vandenstock@med.kuleuven.be.

https://doi.org/10.1523/JNEUROSCI.0634-18.2018

Copyright $\odot 2018$ the authors $\quad 0270-6474 / 18 / 389264-12 \$ 15.00 / 0$
Table 1. Demographic and neuropsychological test results ${ }^{a}$

\begin{tabular}{|c|c|c|c|c|c|c|}
\hline & \multicolumn{2}{|c|}{ Controls } & \multicolumn{2}{|c|}{ Right ATL } & \multicolumn{2}{|c|}{ Left ATL } \\
\hline & Mean & $(S D)$ & Mean & (SD) & Mean & (SD) \\
\hline Age & 54.3 & 8.0 & 52.3 & 10.6 & 52.3 & 8.3 \\
\hline $\operatorname{Sex}(M / F)$ & \multicolumn{2}{|c|}{$5 / 7$} & \multicolumn{2}{|c|}{$8 / 2$} & \multicolumn{2}{|c|}{$4 / 6$} \\
\hline Resection type (SAH/ATL) & \multicolumn{2}{|c|}{ NA } & & & \multicolumn{2}{|c|}{$0 / 10$} \\
\hline Seizure onset & \multirow{2}{*}{\multicolumn{2}{|c|}{ NA }} & 13 & 9.8 & 11.9 & 11.5 \\
\hline Time since surgery & & NA & 9.8 & 4.7 & 11.2 & 3.2 \\
\hline BDI & 4.9 & 4.8 & 4.6 & 6.1 & 8.0 & 7.7 \\
\hline \multicolumn{7}{|l|}{ PANAS } \\
\hline Negative Affect & 16.2 & 5.2 & 16.9 & 7.6 & $25.9^{b}$ & 9.3 \\
\hline Positive Affect & 37.3 & 7.8 & 34.7 & 8.0 & 32.4 & 4.5 \\
\hline MMSE & 29.6 & 0.8 & 27.7 & 2.8 & $28.0^{c}$ & 1.1 \\
\hline \multicolumn{7}{|l|}{ RAVLT } \\
\hline A1-A5 & 50.1 & 9.9 & 45.0 & 13.1 & 36.9 & 11.9 \\
\hline$\%$ recall & 88.8 & 11.7 & 71.6 & 22.9 & $53.5^{c}$ & 35.8 \\
\hline Recognition & 14.4 & 1.2 & 13.8 & 2.8 & 13.4 & 2.2 \\
\hline BNT & 57.9 & 1.9 & 54.3 & 4.8 & $50.2^{c}$ & 5.7 \\
\hline AVF & 25.9 & 5.6 & 22.6 & 5.3 & 20.1 & 3.1 \\
\hline \multicolumn{7}{|l|}{ TMT } \\
\hline$A(s)$ & 27.6 & 8.0 & 30.8 & 15.1 & 29.5 & 8.0 \\
\hline$B(s)$ & 55.3 & 18.0 & 65.9 & 53.3 & 55.6 & 15.9 \\
\hline
\end{tabular}

aSAH, Selective amygdalohippocampectomy; BDI, Beck Depression Inventory; RAVLT, Rey's Auditory Verbal Learning Test; BNT, Boston Naming Test; AVF, Animal Verbal Fluency; TMT, Trail Making Test.

${ }^{b}$ Left ATL patients had significantly higher scores on PANAS for negative affect than both controls and right ATL patients.

¿Left ATL patient performed significantly worse than controls on MMSE, RAVLT (\% Recall), and BNT.

reveal whether intact amygdala are necessary for body expression recognition; and (2) to reveal effects at distance in neural activity and decoding accuracy of ATL resections during body expression perception in body-responsive areas as well as at the whole-brain level.

\section{Materials and Methods}

\section{Participants}

A total of 20 patients who had previously undergone unilateral surgical resection due to mesial temporal lobe epilepsy were recruited through the epileptic surgery database of University Hospitals Leuven, Belgium. Demographics are presented in Table 1. All patients had an extensive history of uncontrollable epilepsy before surgery, with an average onset of seizure at 12.4 years of age ( $\mathrm{SD}=2.3$ years). Ten ( 4 male and 6 female) and 7 (6 male and 1 female) participants underwent, respectively, a left and right unilateral anterior temporal lobectomy. Two male participants underwent a right amygdalo-hippocampectomy. One female patient had a right-sided tumor resection, including the amygdala and hippocampus. The lesion overlap map is displayed in Figure 1. The time since surgery was variable with a mean length of 10.5 years $(S D=0.9$ years). All patients were seizure free at the time of scanning. Six patients were medication free at the time of scanning. The remaining patients were prescribed levetiracetam $(n=7)$, valproate $(n=2)$, carbamazepine $(n=7)$, lamotrigine $(n=2)$, topiramate $(n=1)$, pregabaline $(n=1)$, and clonazepam $(n=2)$. Exclusion criteria for patients were generalized cognitive impairment (IQ $<80$ ), major DSM axis I psychopathology, other neurological conditions than epilepsy, or major somatic disorders. The healthy control group (5 male and 7 female) was recruited using the hospital coworkers' internal advertisement service. Controls were matched for mean age and sex ratio with the patient group (Table 1), had no self-reported major DSM axis I psychopathology, neurological, or somatic disorder, and did not take any psychotropic medication.

To document any cognitive changes following ATL resection, we performed a cognitive assessment, including global cognitive ability (Mini Mental State Examination [MMSE]), verbal memory (Rey's Auditory Verbal Learning Test), categorical verbal fluency (Animal Verbal Fluency), and visual divided attention and task shifting (Trail Making Test A and B). Participants also completed a mood (Beck Depression Inventory) and affect (Positive and Negative Affect Scale [PANAS]) questionnaire. All but 1 right resection patient and 1 control were right handed as 


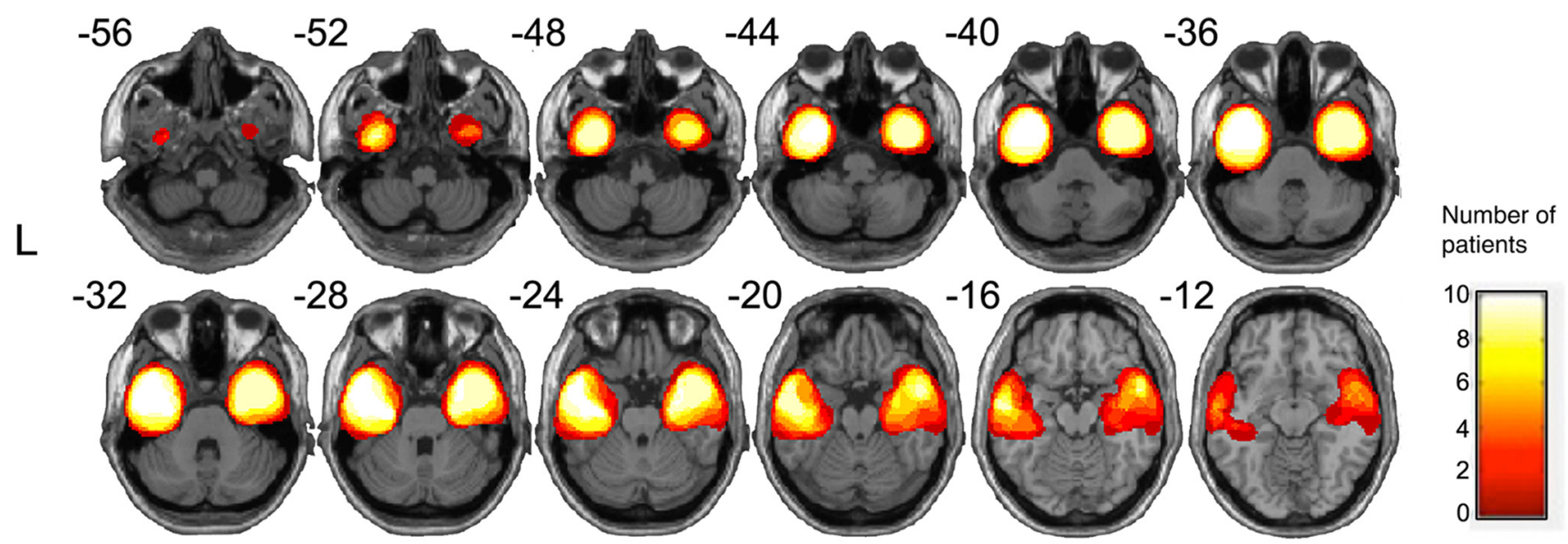

Figure 1. Lesion overlap in patients with unilateral resection of ATL.

assessed through the Edinburgh Handedness Inventory. All participants had normal or corrected-to-normal visual acuity.

The study was conducted in accordance with the Declaration of Helsinki, and all participants gave written informed consent. The ethical committee of University Hospitals Leuven approved the study.

\section{Experimental design}

Stimuli. The stimuli have been described in detail previously (Jastorff et al., 2015, 2016). In short, they consisted of video clips displaying puppet models of walking humans. They were constructed using motion capture data of emotionally expressive (angry, fearful, sad, and happy) and neutral gaits. An animated custom-built volumetric puppet model was built and rendered in MATLAB (The MathWorks) (for details, see Roether et al., 2009). These stimuli served as prototypes for subsequent emotion morphing (Giese and Poggio, 2000; Jastorff et al., 2006). The complete set of prototypical stimuli contained 30 stimuli, six examples of 5 conditions (angry, happy, sad, fearful and neutral). We used a continuum of expressions ranging from $100 \%$ neutral prototype to $125 \%$ emotional prototype. For frame examples of stimulus prototypes and different morph levels, see Figure 2.

Scrambled versions of the stimuli were created by decomposing the figure and rearranging the individual geometric shapes. A constant random offset in horizontal or vertical direction was added to the original movement of the geometric shapes forming the puppet model. In half of the stimuli, the shapes translated horizontally, whereas in the other half the shapes translated vertically. The speed of each shape was the average speed of all shapes in the original stimulus. Thus, in both conditions, the global motion energy was matched (for stimulus examples, see Movies $1-3)$.

Behavioral experiments. Morphed stimuli were displayed on an LCD screen $(60 \mathrm{~Hz}$ frame rate; $1600 \times 1200$ pixels resolution) that was viewed binocularly from a distance of $40 \mathrm{~cm}$, producing a stimulus size of $\sim 7$ degrees visual angle. Stimulus presentation and recording of the participants' responses were implemented with the MATLAB Psychophysics Toolbox (Brainard, 1997). The stimuli were shown against a uniform gray background (Fig. 2).

A trial consisted of presentation of a stimulus at the center of the screen for $10 \mathrm{~s}$. No fixation requirements were imposed. Participants were instructed to categorize the stimulus as happy, angry, fearful, or sad by pressing 1 of 4 labeled buttons, indicating their choice for the corresponding emotion category. Participants were instructed to respond as soon as they had made their decision, but we did not emphasize responding quickly. If the participant answered within $10 \mathrm{~s}$, stimulus presentation was terminated immediately; otherwise, it halted after $10 \mathrm{~s}$ and a uniform gray screen was shown until the subject entered a response. After a $1.5 \mathrm{~s}$ intertrial interval, the next trial started. The experiment started with a demonstration session where subjects were familiarized with the stimuli for a maximum of 12 trials ( 3 trials per emotion). No feedback regarding performance was provided during the entire experiment.
We used a 1-up-1-down staircase procedure to calculate individual emotion detection thresholds for every emotion separately. The initial test level was set at $50 \%$ emotion for each staircase. Emotions were shown in a random order. When participants answered correctly, test level increased with 5\% (a 5\% less emotional stimulus was shown), when they answered incorrectly, test level decreased with 5\% (a 5\% more emotional stimulus was shown). The minimal test level for each emotion was $0 \%$, and the maximal test level was $125 \%$. These motion morphs were derived from 6 different prototypical stimuli for each emotion category, as was described above. When the boundaries were hit 4 times for a particular emotion, the presentation of this emotion was stopped. Otherwise, it stopped after 10 reversals of the staircase or after 35 trials per emotion. Hence, the number of trials and selection of stimuli per emotion category were dependent on the responses of the participants. Individual emotion detection thresholds were calculated for each emotion based on the reversal values of the 4 staircases. Each threshold represents the mean of 10 reversals and is an estimate of the 50\% correct performance level. To obtain a general emotion detection threshold, thresholds were averaged over the four emotions for each subject.

We added a control experiment similar to the emotion task in terms of stimuli and display parameters. Stimuli consisted of motion morphs derived from neutral walking and neutral running prototypes and the instruction stated to categorize the stimuli as walking or running. This task allows investigating the specificity of any emotion processing deficits (Jastorff et al., 2016; Van den Stock, 2018).

fMRI task. Prototypical avatars (i.e., 100\% emotional) expressing the four emotions and a neutral condition were presented against a black background in an event-related oddball paradigm (Fig. 2). As an oddball, we added a neutral backwards-walking avatar. Stimuli appeared centrally on the screen for 1.5-5.0 s followed by an interstimulus interval (ISI) of variable length (2.3-5.0 s, determined by an exponential function) (Dale, 1999), displaying only a red fixation dot. In each run, each stimulus was presented at two different sizes. Two different sizes were used to minimize the effect of low-level features, such as retinal position on the fMRI activations. Twelve null trials (baseline) were randomly interspersed presenting only the fixation dot for $3 \mathrm{~s}$. The oddball was shown 6 times. Participants were asked to press a button every time the oddball appeared. Four functional runs were recorded per participant. To familiarize with the stimuli, all participants watched some stimuli before the experiment. The order of experiments (behavioral/fMRI) was counterbalanced between participants.

Localizer experiment. To study emotion effects in independently defined body-responsive ROIs, we performed one localizer run for each participant in addition to the experimental runs. The localizer consisted of two stimulus conditions: intact prototypical (neutral and emotional) stimuli and scrambled versions of these prototypical stimuli, both organized in separate blocks with duration of $15 \mathrm{~s}$. The stimulus duration varied across stimuli but was matched between scrambled and intact 
A

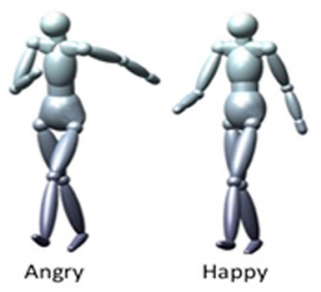

C
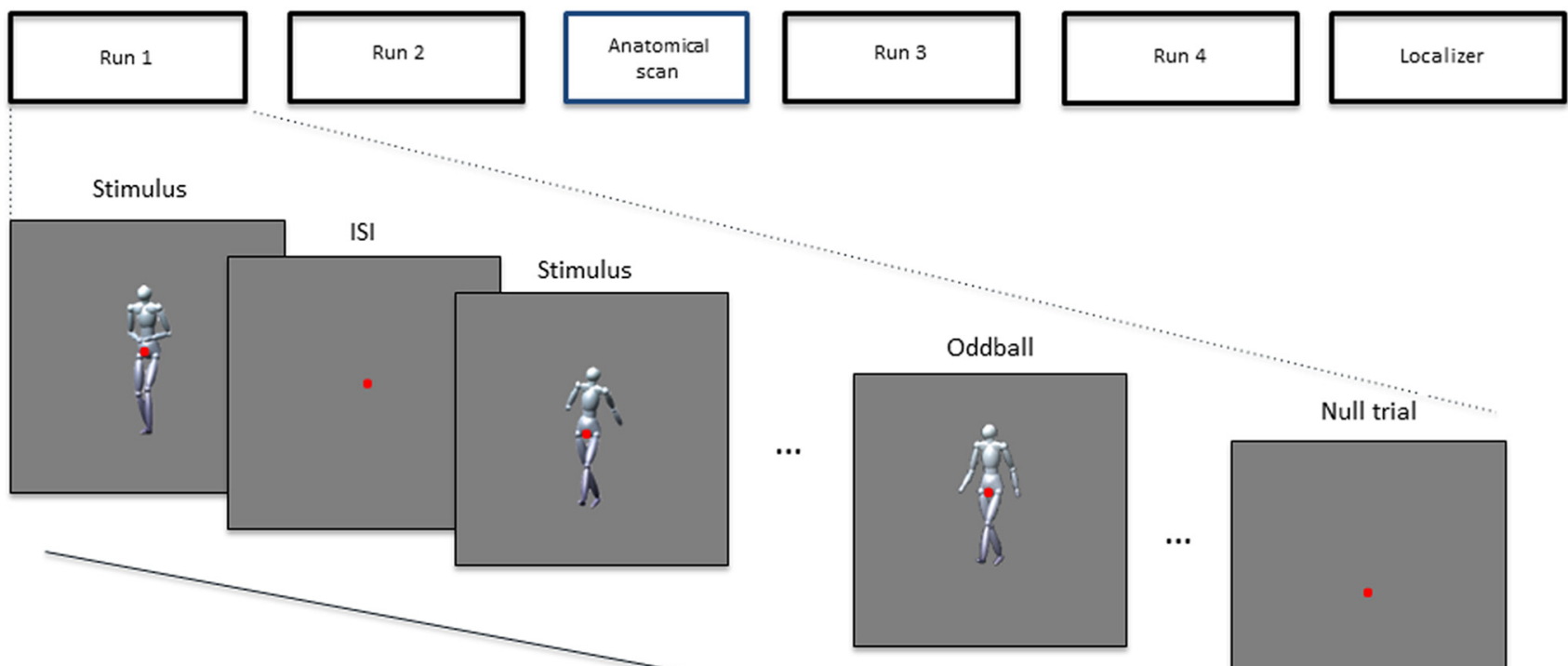

$|S|$
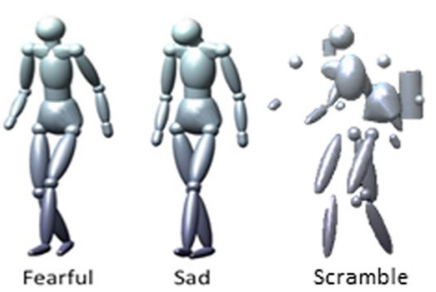

B
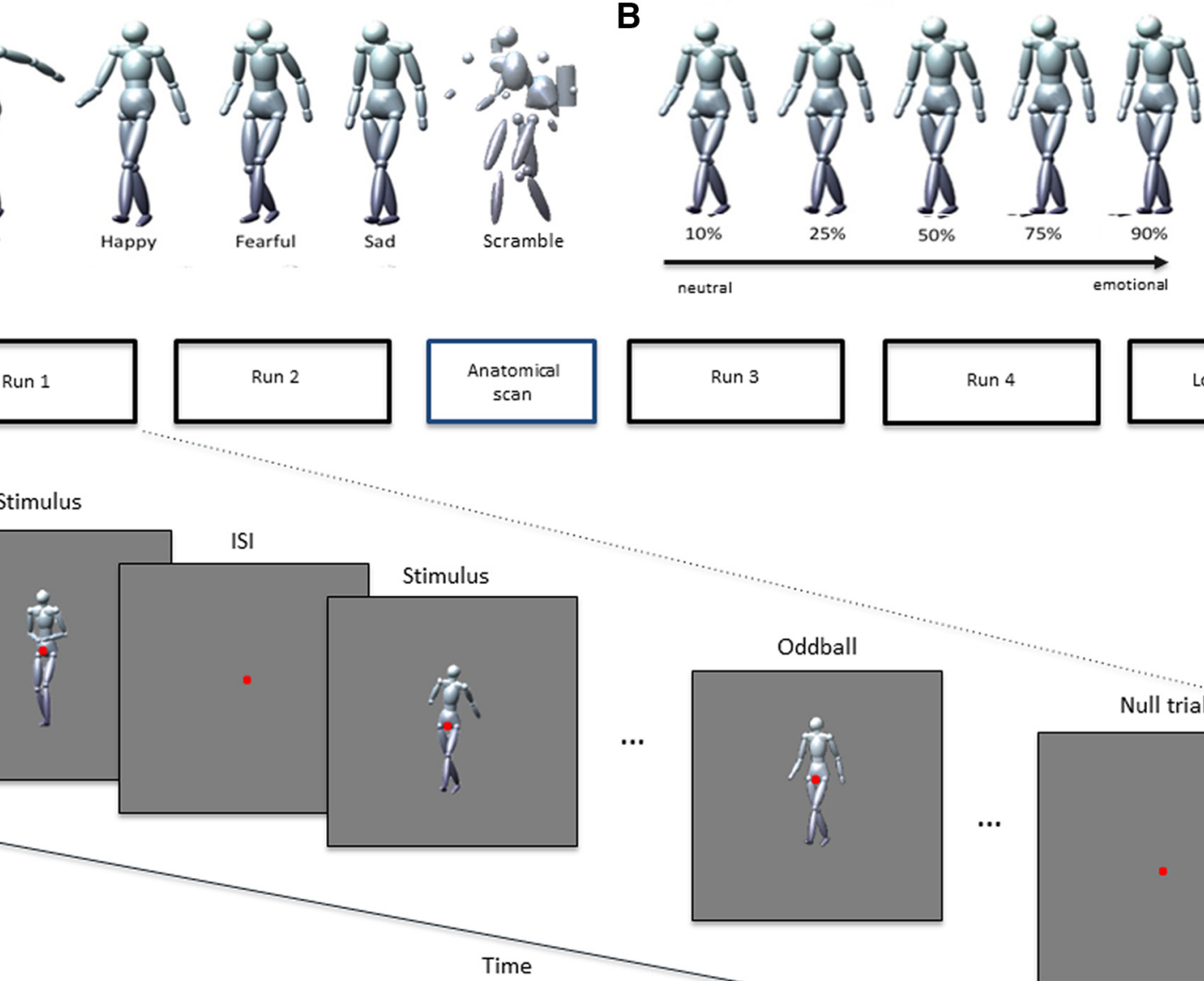

Figure 2. Static frames of $(\boldsymbol{A})$ prototypical and $(\boldsymbol{B})$ morphed stimulus examples. $\boldsymbol{B}$, Different morph levels between neutral and emotional (sad) gaits as used during the behavioral experiment. C, Schematic overview of imaging procedure: four functional emotion scans were interspersed by a high-resolution anatomical scan and followed by a functional localizer scan. Bottom, Event-related experimental fMRI design. Trials consisted of $1.5-5 \mathrm{~s}$ clips with an ISI between 2.3 and 5 s. The oddball stimulus was a neutral backwards-walking avatar.

blocks with a $500 \mathrm{~ms}$ ISI. Blocks were separated by an ISI of 6-7 s (baseline). The run consisted of 16 stimulation blocks, eight of every condition. Participants were instructed to fixate a red fixation dot in the center of the screen during the entire run.

MRI data acquisition. Structural and functional images were collected on a 3T Philips achieva dstream scanner with a 32-channel receive-only headcoil. A standard EPI sequence was used to acquire the functional runs $\left(\mathrm{TR}=2 \mathrm{~s}, \mathrm{TE}=30 \mathrm{~ms}\right.$, flip angle $=90^{\circ}, 36$ slices, $0.3 \mathrm{~mm}$ interslice gap, $2.75 \mathrm{~mm} \times 2.75 \mathrm{~mm} \times 3.5 \mathrm{~mm}$ voxel size). All functional scans were preceded by 4 dummy scans to allow for magnetization to reach equilibrium state. During the scan session, a high-resolution T1-weighted anatomical image $\left(\mathrm{TR}=9.7, \mathrm{TE}=4.6\right.$, flip angle $=8^{\circ}, 182$ slices, matrix size $256 \times 256,1 \mathrm{~mm} \times 1 \mathrm{~mm} \times 1 \mathrm{~mm}$ voxel size) was acquired.

\section{Statistical analysis}

Behavioral data analysis. Neuropsychological data as well as data from the control task were analyzed by means of one-way ANOVAs using IBM SPSS Statistics, version 24 . To assess group differences in emotion recognition, linear mixed-models analyses with random intercept and fixed effects for group, emotion, and group $\times$ emotion were performed on the emotion detection thresholds. All post hoc tests were performed with a Bonferroni correction.

fMRI data analysis. All data were analyzed using statistical parametric mapping (SPM12, Wellcome Trust Center for Neuroimaging, London) within MATLAB. Data were slice time-corrected, motion-corrected (aligned to the mean image across runs), and coregistered to the subject's high-resolution anatomical image. Images were then normalized to MNI space with a voxel size of $2 \mathrm{~mm} \times 2 \mathrm{~mm} \times 2 \mathrm{~mm}$ using New Segment with an extra prior (the mean of white matter and CSF Tissue probability maps) (Ripollés et al., 2012) and DARTEL. Data were smoothed using an $8 \mathrm{~mm}$ isotropic Gausian Kernel.

For each participant, all conditions with durations and onsets were entered in a GLM, yielding a design matrix containing 6 regressors modeling the 6 conditions (four emotions + neutral + fixation (baseline)). Head movement parameters, obtained from the motion correction during preprocessing, were entered as a regressor-of-no-interest for each run. To exclude variance due to the oddball and the subjects' response, two additional regressors were added to the model: the appearance of the oddball and the subsequent button press during the ISIs. On the subject level, all regressors were convolved with the canonical hemodynamic response function. We calculated contrasts for each participant for each of the four emotional conditions versus neutral and the average of all four emotional conditions versus neutral. Data were further analyzed at second level through ANOVA using a full factorial design. Factors consisted of group (3 levels: controls, right resection, and left resection) and emotion (4 levels: angry vs neutral, fear vs neutral, sad vs neutral, and happy vs neutral). Statistical threshold was set at $P_{\text {height }}<0.05$, FWE-corrected, cluster extent of 20 voxels. The following effects were investigated: the effect of emotion (i.e., a one-sample $t$ test on each of the four emotions vs neutral contrasts) in each group separately; effect of emotion in controls versus right resected patients (i.e., a two-sample $t$ test on each of the four emotions vs neutral contrasts between controls and right resected patients); effect of emotion in controls versus left resected patients; and 


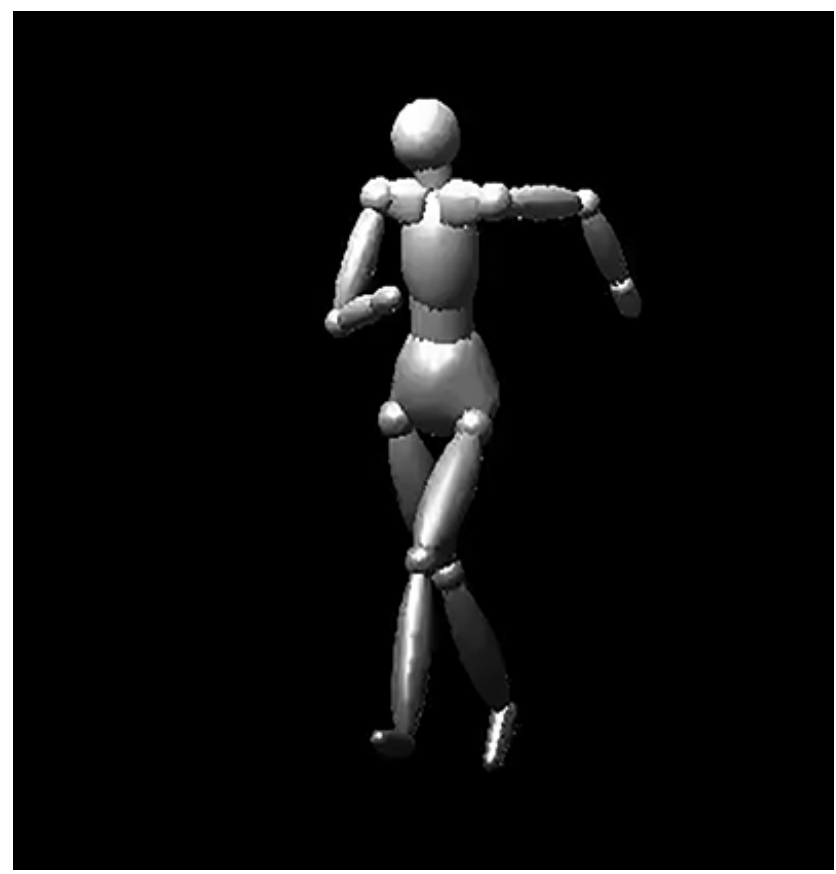

Movie 1. Stimulus example of a prototypical anger expression.

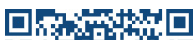
$4 y_{1}+4$ 政 15

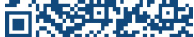

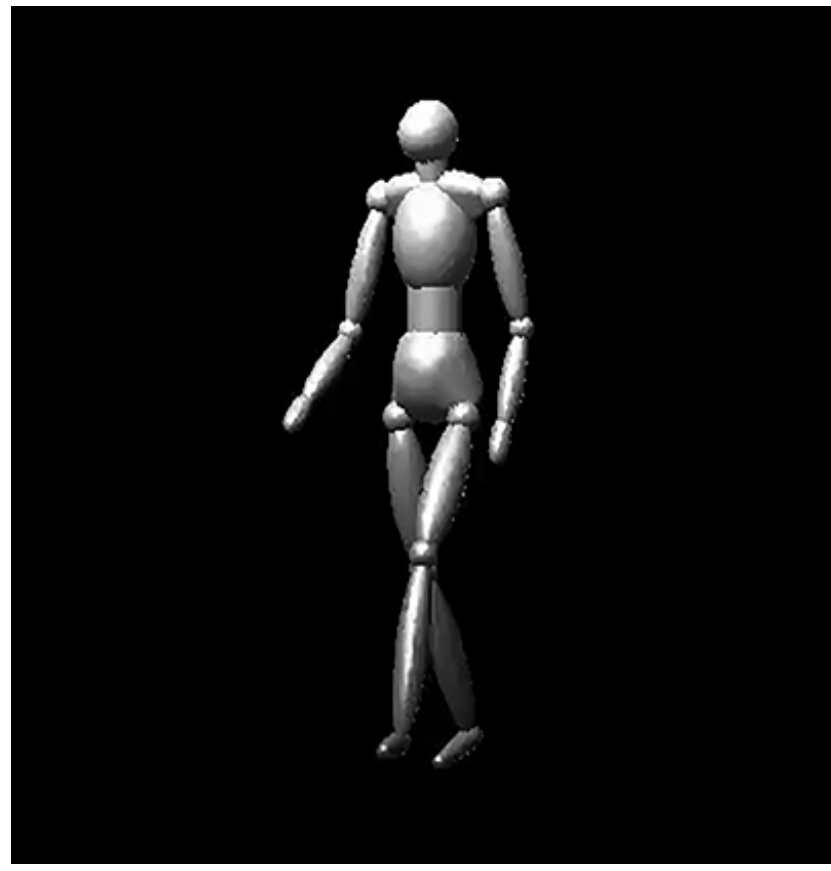

Movie 2. Stimulus example of a prototypical neutral expression.

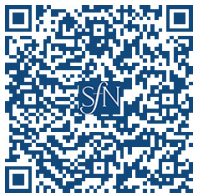

effect of emotion in left versus right resected patients. In addition, all inverse group effects were also investigated.

Data from the localizer were preprocessed in a similar way to the data from the experimental runs, yielding a design matrix containing three

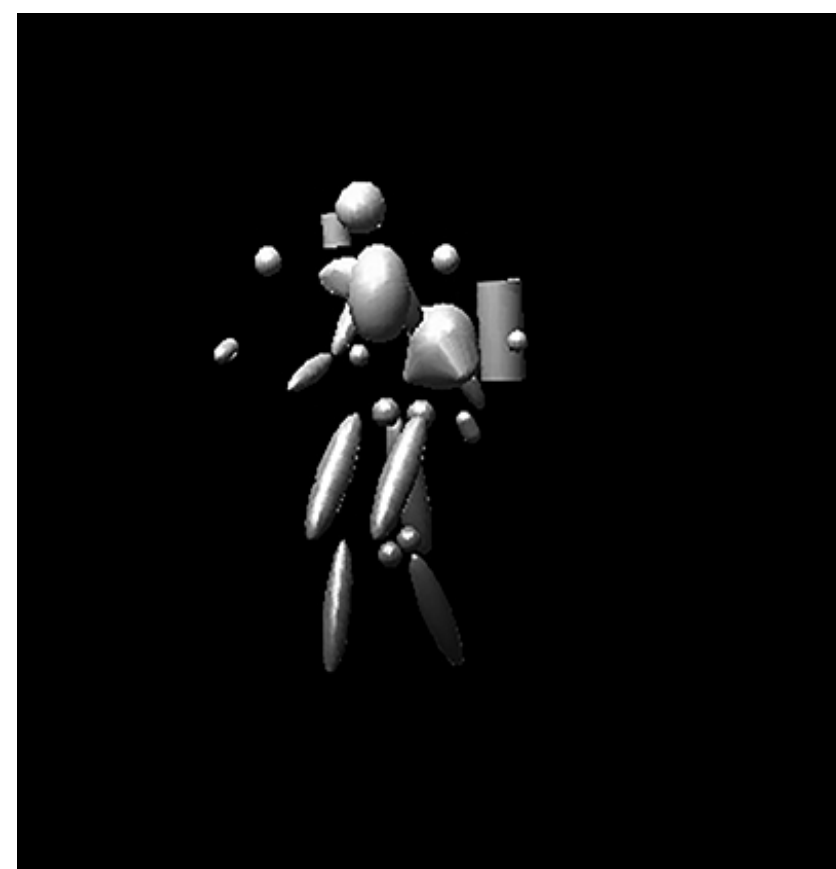

Movie 3. Stimulus example of a scrambled stimulus.

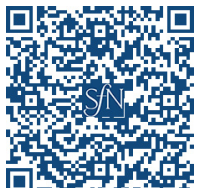

regressors modeling the three conditions (bodies, scrambles, and baseline). The contrast "bodies vs scrambles" was calculated for each subject. Subsequently, a random-effects analysis was performed on the parameter estimates of activity for this contrast across participants over the whole group (controls and patients) using a one-sample $t$ test. Threshold was set at $P_{\text {height }}<0.001$, uncorrected with a minimal cluster extent of 100 voxels. Subsequently, ROI analyses by means of small volume corrected (SVC) contrasts were performed to investigate group differences in emotion response in the body-responsive ROIs defined by the localizer. The mean percent signal change (PSC) was calculated for the average of the four emotional conditions relative to baseline as well as for the neutral condition relative to baseline by averaging the PSC within each of these predefined ROIs using Marsbar (Brett et al., 2002). Group differences were investigated using a linear mixed model with random intercept and fixed effects for group, ROI, and group $\times$ ROI. All post hoc tests were performed with a Bonferroni correction.

To investigate functional coupling between amygdala and bodyresponsive regions, we correlated fitted responses in right and left amygdala with fitted responses in body-responsive ROIs in the healthy control group only. Fitted responses were computed for all contrasts at the peak voxels in the ROIs as derived from the localizer experiment. Consequently, we calculated Spearman correlations between the fitted responses in every ROI to investigate connectivity between the ROIs in healthy controls.

MVPA. To investigate whether body-responsive brain regions contain information for emotion categorization, MVPA analyses were performed in MNI space on unsmoothed data. We used the decoding toolbox (Hebart et al., 2014) to assess performance in classification between emotional and neutral stimuli as well as between the four emotional conditions based on predefined $t$ contrasts and $\beta$ values, respectively, in the ROIs defined by the localizer.

To this end, we first calculated a contrast for the average of all four emotional conditions versus baseline and the neutral condition versus baseline per run per subject. The resulting $t$ maps were loaded into the toolbox, which then subsequently used all runs to test and to train on a leave-1-run-out basis. To assess classification between the four emotions, 
A

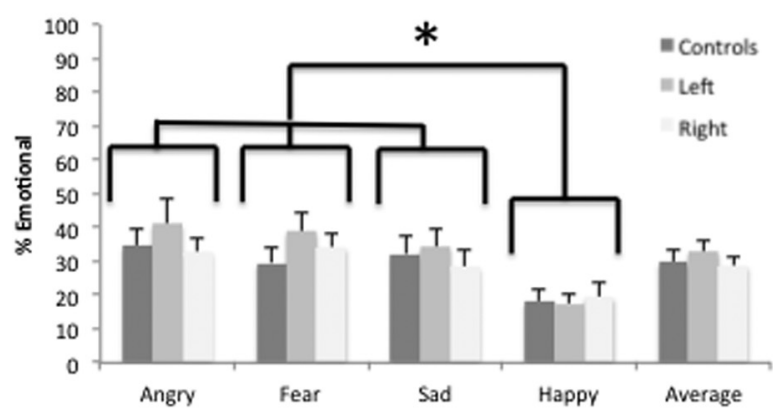

B

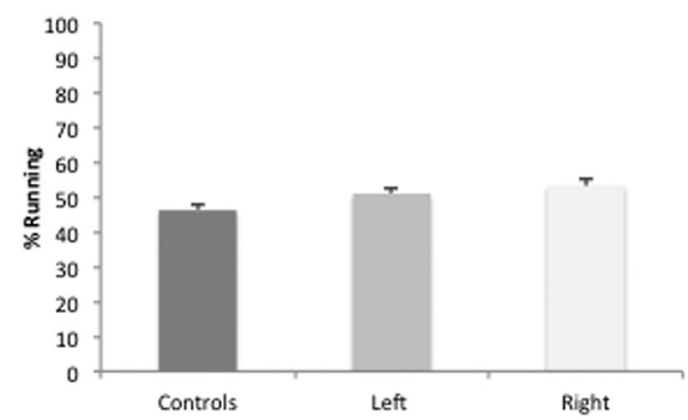

Figure 3. Behavioral results. ${ }^{*} p<.001$. Detection thresholds are displayed per group for the emotion task $(\boldsymbol{A})$ and control task $(\boldsymbol{B})$. Detection thresholds reflect an estimate of the emotional intensity required to obtain a $50 \%$ correct performance level. The average detection threshold is calculated over emotions to represent a general emotion detection threshold.
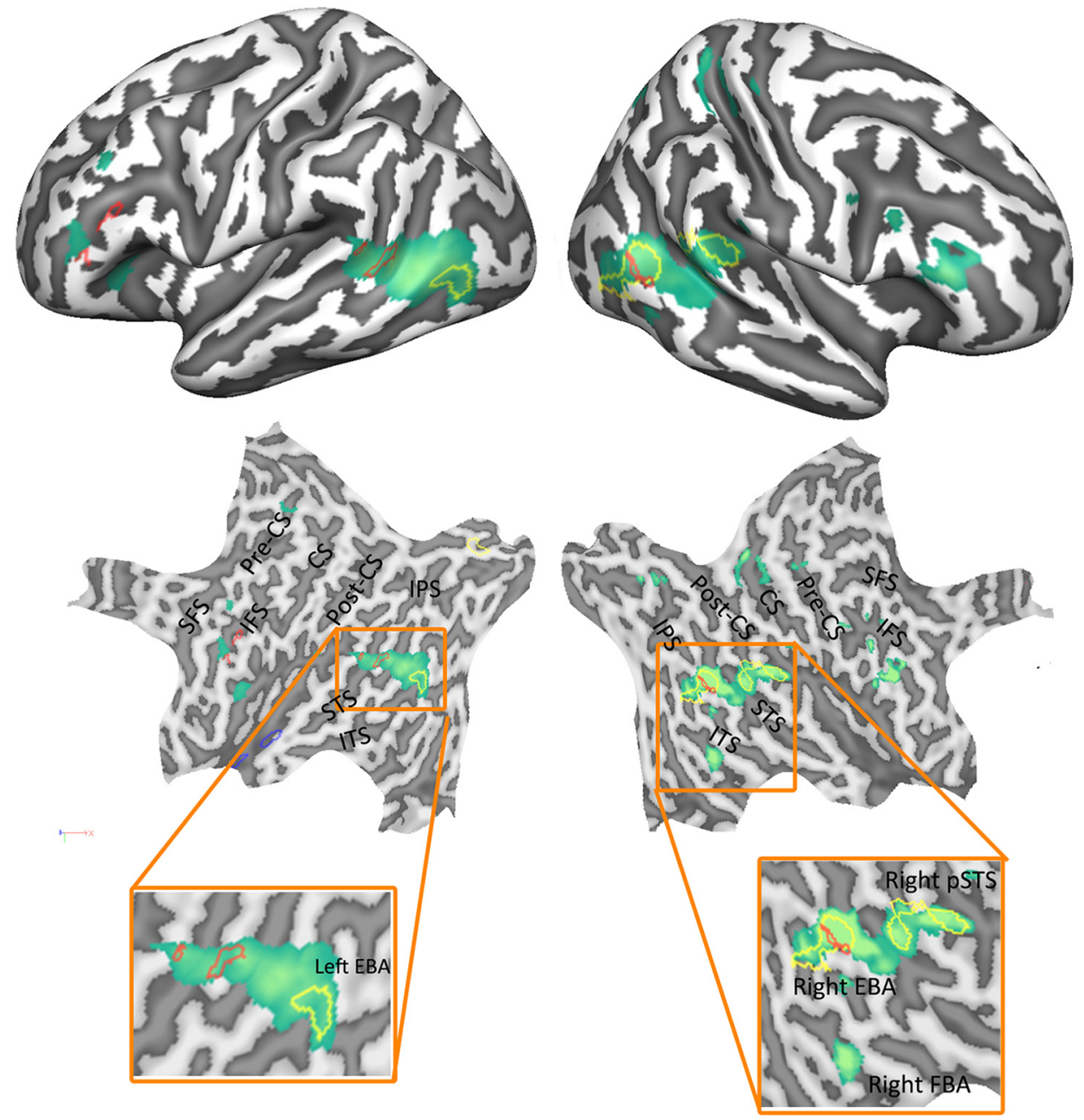

10.16

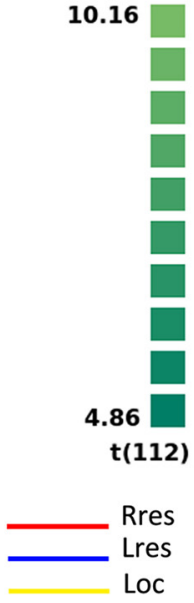

Figure 4. Emotion effect (i.e., a one-sample $t$ test on the average of each of the four emotions vs neutral contrasts) as a function of group. The statistical map displays the emotion effect in the control group. Red and blue outlines indicate the significant clusters in the right and left ATL resection groups, respectively. Yellow outlines indicate body-sensitive regions defined by means of the localizer in the total sample.

the parameter estimates of each emotional condition per run were loaded into the toolbox. The toolbox used these parameter estimates of all four runs to test and train in a leave-1-run-out basis.

Subsequently, we conducted a linear mixed-models analysis with random intercept and fixed effects for group, ROI, and group $\times$ ROI on the accuracy-minus-chance values. All post hoc tests were performed with a Bonferroni correction.
Parametric testing of all nonvoxelwise analyses always depended on the results of a normality check by means of Shapiro-Wilk test and visual inspection of the QQ plot. These were either performed on the variables or on the unstandardized residuals of linear mixed-models analyses. If homogeneity of variances could not be assumed based on Levene's test, a Welch test was performed and $95 \%$ CIs are reported as an estimate of effect size. 


\section{Results}

\section{Neuropsychological testing}

Results are presented in Table 1. There was a significant effect of group for $\operatorname{MMSE}\left(F_{(2,14.155)}=7.374, p=0.006\right)$, Boston Naming Test $\left(F_{(2,13.338)}=9.003, p=0.003\right)$, the Auditory Verbal Learning Test (\% Recall: $\left.F_{(2,14.191)}=5.860, p=0.013\right)$, and the Animal Verbal Fluency $\left(F_{(2,28)}=3.642, p=0.039, \eta^{2}=0.206\right)$. Post hoc tests revealed that, compared with controls, left ATL patients were moderately impaired on $\operatorname{MMSE}\left(t_{(2)}=3.583, p=0.01,95 \%\right.$ CI $[0.4051,2.7616])$, Boston Naming Test $\left(t_{(2)}=3.910, p=\right.$ $0.008,95 \%$ CI $[2.236,13.152])$, Auditory Verbal Learning Test (\% Recall: $t_{(2)}=2.990, p=0.032,95 \%$ CI $\left.[0.0324,0.6746]\right)$, and the Animal Verbal Fluency $\left(t_{(2)}=2.663, p=0.038,95 \% \mathrm{CI}\right.$ $[0.2548,11.3563])$. These findings are in accordance with the function of the resected area (i.e., semantic memory) and were used as regressors of no interest in further analysis.

There was no significant group effect of Beck Depression Inventory score $\left(F_{(2,28)}=0.927, p=0.408\right)$, but a significant group effect on the PANAS for negative affect $\left(F_{(2,28)}=5.503, p=0.10\right.$, $\left.\eta^{2}=0.282\right)$. Post hoc tests revealed that patients with left ATL scored significantly higher on the PANAS for negative affect than patients with right $\operatorname{ATL}\left(t_{(2)}=2.647, p=0.04,95 \%\right.$ CI [0.3412, $17.6810])$ and controls $\left(t_{(2)}=3.068, p=0.014,95 \%\right.$ CI [ 1.6539 , $17.8128]$ ). This score was also used as a regressor of no interest in further analysis.

\section{Body emotion recognition experiment}

Linear mixed-model analysis on the emotion detection thresholds was performed with MMSE, AVLT, BNT, AVF, and PANASnegative affect score as variables of no interest. This did not reveal a significant group effect in the emotion recognition task $\left(F_{(2,96)}=0.195, p=0.823\right)$, nor any group $\times$ emotion interaction $\left(F_{(6,49)}=0.456, p=0.837\right)$. There was, however, a significant effect of emotion $\left(F_{(3,49)}=11.522, p<0.001\right)$. Post hoc tests revealed that better performance on "happy" than on the three other emotions: happy versus angry $\left(t_{(40.956)}=-4.83, p<\right.$ $0.001,95 \%$ CI $[-29.753,-7.240])$, happy versus $\operatorname{sad}\left(t_{(44.018)}=\right.$ $-3.60, p=0.004,95 \% \mathrm{CI}[-23.761,-3.454])$, and happy versus fear $\left(t_{(44.451)}=-4.29, p<0.001,95 \%\right.$ CI $\left.[-25.325,-6.060]\right)$. Results are presented in Figure 3.

\section{Imaging results}

Because of technical failure, 1 patient with a left-sided resection was excluded from further analysis. For the oddball detection task, all subjects obtained a maximum of 6 hits ( 6 oddballs) per run.

\section{Body-responsive regions}

Based on the localizer data of the entire sample, we defined bilateral EBA and right pSTS (Fig. 4, yellow outline). A logical conjunction analysis (requiring significant activations in all groups) revealed that both bilateral EBA and right pSTS were activated in the three groups $\left(P_{\text {height }}<0.01\right.$, uncorrected $)$.

\section{Within-group emotion effects}

Control subjects. An emotion effect (i.e., a one-sample $t$ test on the average of the four emotions vs neutral contrasts) in healthy controls was observed in a large bilateral cluster in lateral occipitotemporal cortex, overlapping EBA and pSTS, in addition to smaller distributed clusters: bilateral inferior frontal gyrus, precuneus, superior parietal lobule, supplementary motor areas, right fusiform, postcentral and superior temporal gyrus, left insula, and middle frontal gyrus. At the subcortical level, there was
Table 2. Whole-brain fMRI results for the emotion effect (i.e., a one-sample $t$ test on the average of each of the four emotion contrasts) in healthy controls ${ }^{a}$

\begin{tabular}{|c|c|c|c|c|c|c|c|}
\hline \multirow[b]{2}{*}{ Region } & \multirow[b]{2}{*}{ Hemisphere } & \multicolumn{3}{|c|}{ Coordinates } & \multirow[b]{2}{*}{$t$} & \multirow{2}{*}{$\begin{array}{l}\text { No. of } \\
\text { voxels }\end{array}$} & \multirow[b]{2}{*}{$p$} \\
\hline & & $x$ & $y$ & $z$ & & & \\
\hline \multirow[t]{6}{*}{ LOC } & $\mathrm{L}$ & -54 & -64 & 4 & 10.16 & 1636 & $>0.001$ \\
\hline & & -52 & -74 & 8 & 8.64 & & \\
\hline & & -62 & -50 & 8 & 8.39 & & \\
\hline & $\mathrm{R}$ & 46 & -64 & 8 & 9.17 & 1831 & $>0.001$ \\
\hline & & 50 & -54 & 0 & 7.72 & & \\
\hline & & 62 & -38 & 16 & 7.52 & & \\
\hline \multirow[t]{2}{*}{ IFG } & $\mathrm{R}$ & 54 & 30 & 8 & 8.91 & 453 & $>0.001$ \\
\hline & & 56 & 32 & 22 & 6.46 & & \\
\hline FG & $\mathrm{R}$ & 46 & -48 & -18 & 7.93 & 349 & $>0.001$ \\
\hline \multirow[t]{3}{*}{ SPL } & $\mathrm{R}$ & 22 & -50 & 66 & 6.98 & 220 & $>0.001$ \\
\hline & & 34 & -34 & 56 & 5.87 & & \\
\hline & & 32 & -46 & 60 & 5.87 & & \\
\hline Precun & $\mathrm{R}$ & 18 & -76 & 54 & 6.62 & 75 & $>0.001$ \\
\hline IFG & $\mathrm{R}$ & 44 & 12 & 30 & 6.53 & 156 & $>0.001$ \\
\hline MFG & L & -48 & 32 & 36 & 6.25 & 49 & 0.001 \\
\hline IFG & L & -38 & 32 & 2 & 6.17 & 312 & $>0.001$ \\
\hline SOG & L & -36 & -86 & 26 & 5.92 & 51 & 0.001 \\
\hline Amygdala & $\mathrm{R}$ & 26 & -2 & -12 & 5.91 & 28 & 0.004 \\
\hline \multirow[t]{2}{*}{$\mathrm{OFC}$} & $\mathrm{R}$ & 32 & 38 & -10 & 5.88 & 79 & $>0.001$ \\
\hline & & 24 & 36 & -10 & 5.19 & & \\
\hline Amygdala & L & -20 & -6 & -16 & 5.75 & 54 & 0.001 \\
\hline SMA & $\mathrm{R}$ & 10 & -4 & 68 & 5.74 & 36 & 0.003 \\
\hline Insula & L & -44 & -30 & 18 & 5.72 & 33 & 0.003 \\
\hline STG & $\mathrm{R}$ & 68 & -16 & 8 & 5.71 & 22 & 0.006 \\
\hline SMA & L & -14 & -6 & 70 & 5.61 & 40 & 0.002 \\
\hline PoCG & $\mathrm{R}$ & 64 & -16 & 46 & 5.36 & 23 & 0.006 \\
\hline SPL & L & -30 & -50 & 66 & 5.23 & 20 & 0.007 \\
\hline
\end{tabular}

${ }^{a}$ Whole-brain fMRI results of emotion effect (i.e., a $t$ test comparing each of the four emotions vs neutral contrasts against zero) in healthy controls. Coordinates are $\mathrm{mm}$ in MNI space. LOC, Lateral occipitotemporal cortex; IFG, inferior frontal gyrus; $\mathrm{FG}$, fusiform gyrus; $\mathrm{SPL}$, superior parietal lobule; Precun, precuneus; $\mathrm{MFG}$, middle frontal gyrus; SOG, superior occipital gyrus; OFC, orbitofrontal cortex; SMA, supplementary motor area; STG, superior temporal gyrus; PoCG, postcentral gyrus.

an effect in the amygdala bilaterally. As the cluster in the right fusiform gyrus overlapped with coordinates reported for FBA (Peelen and Downing, 2005), we selected this as an additional ROI. Within the predefined body-responsive regions, we found large clusters in right EBA ( $x=46, y=-64, z=8,316$ voxels), in left EBA $(x=-52, y=-66, z=4,175$ voxels $)$, and $\operatorname{rpSTS}(x=$ $62, y=-38, z=16,348$ voxels) (Figure 4; Table 2).

Amygdalar connectivity with body-responsive regions. We calculated the fitted responses in peak voxels of left and right amygdala and left and right EBA, right pSTS, and right FBA. Spearman correlation analyses were performed and revealed a significant result for the mean of the four emotions compared with neutral between the right amygdala and right EBA ( $\rho=$ 0.783, $N=12, p=0.0075$, one-tailed, Bonferroni-corrected, $95 \%$ CI $[0.333,1])$. Spearman correlation analysis between right amygdala and left amygdala $(\rho=0.615, N=12, p=$ 0.0825 , one-tailed, Bonferroni-corrected) and between right amygdala and right FBA $(\rho=0.587, N=12, p=0.1225$, one-tailed, Bonferroni uncorrected) were not significant. These results confirm previous findings (Peelen et al., 2007) and provide support for the paradigm as a valid tool to investigate modulatory influences between amygdala and bodyresponsive regions.

Right TLE. The effect of emotion (a one-sample $t$ test on the average of the four emotions vs neutral contrasts) in the right resection group revealed significant results in the left superior temporal gyrus, inferior frontal gyrus, and right middle temporal gyrus. ROI analysis revealed only one small cluster in right EBA ( $x=56, y=-66, z=4,28$ voxels), but not in the other two body-selective ROIs (Fig. 4, red outline). 
A
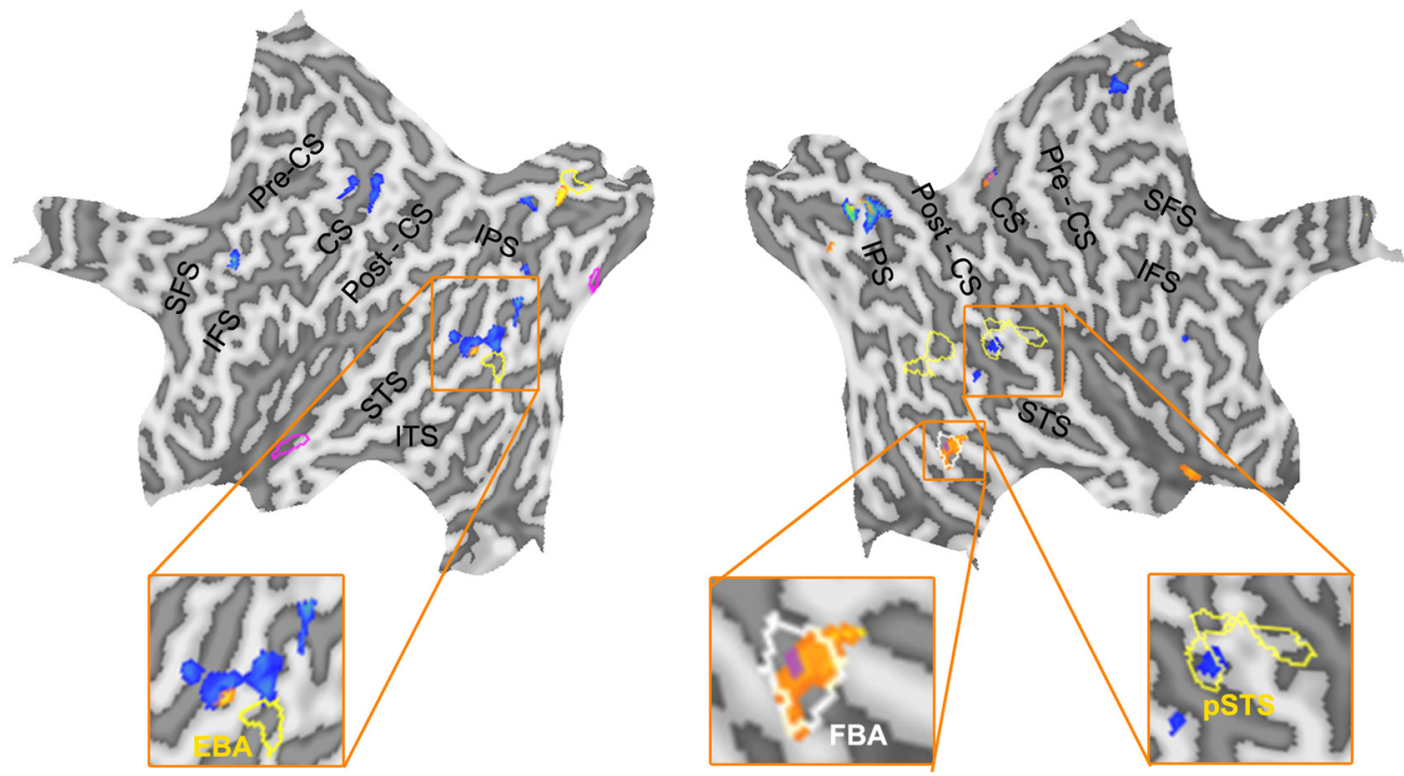

B
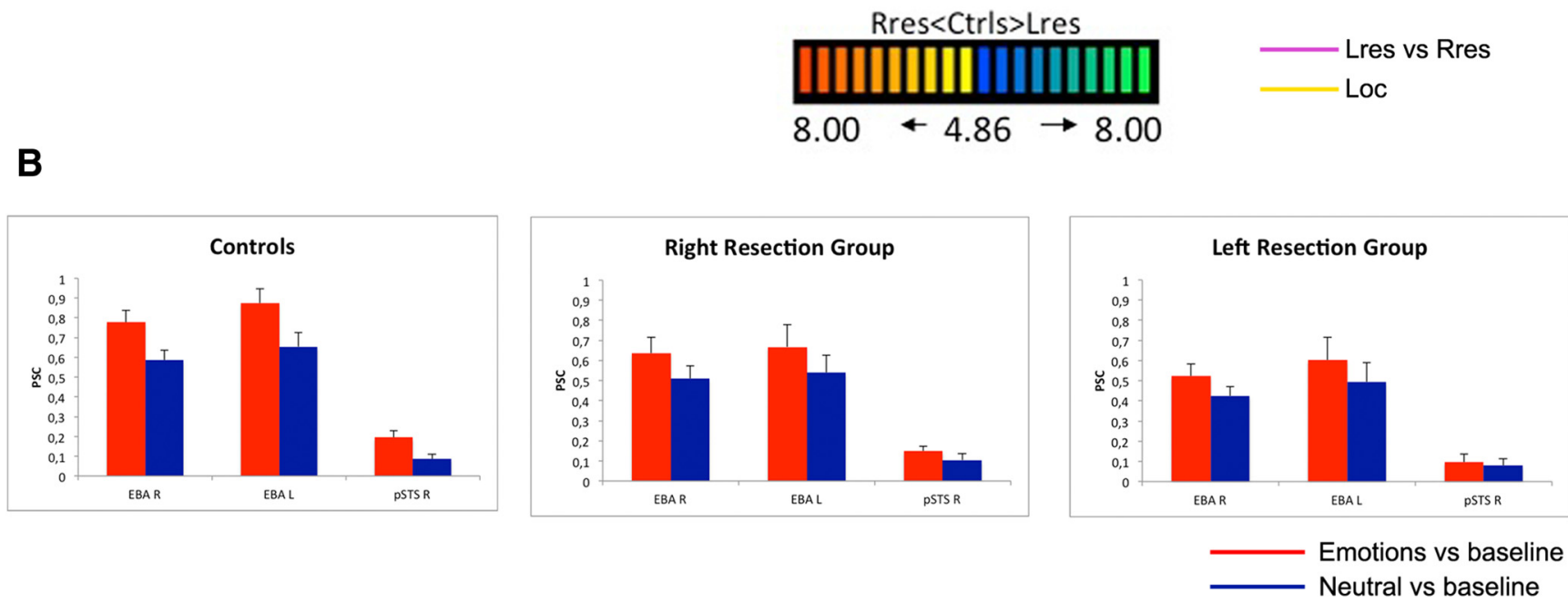

Figure 5. Group comparisons of the emotion effect (i.e., two-sample $t$ tests on the average of each of the four emotions vs neutral contrasts). $A$, Statistical maps displaying stronger emotion effects in the control group on the one hand compared with the right (yellow to red coding) and left (blue to green coding) ATL resection group on the other hand. Pink outlines indicate the areas showing stronger emotion effects in the left compared with the right ATL resection group. Yellow outlines indicate body-sensitive regions defined by means of the localizer in the total sample. $\boldsymbol{B}$, Bar charts represent the PSC for the contrast emotions versus baseline and neutral versus baseline as a function of group and body-sensitive ROI. LH, Left hemisphere; RH, right hemisphere; SFS, superior frontal sulcus; IFS, inferior frontal sulcus; CS, central sulcus; ITS, inferior temporal sulcus; IPS, intraparietal sulcus.

Left TLE. In the left ATL group, we found an effect of emotion in the left parahippocampal gyrus. We did not find any significant activation in the body-responsive ROIs (Fig. 4, blue outline).

\section{Between-group comparisons}

Controls versus right resection group. Compared with the right resection group, healthy controls showed a stronger emotion effect (i.e., a two-sample $t$ test on the average of each of the four emotions vs neutral contrasts) in the bilateral precuneus, the right fusiform, cingulate, and parahippocampal and middle occipital gyrus, as well as in the right caudate nucleus, amygdala, and superior parietal lobule (Fig. 5; Table 3). ROI analyses showed only a small cluster in left EBA $(x=-50, y=-72, z=$ 10,5 voxels). The reverse contrast (right resection groups vs controls) revealed no significant differences in activation.

Controls versus left resection group. Compared with the left resection group, healthy controls showed a stronger emotion effect (i.e., a two-sample $t$ test on the average of each of the four emotions vs neutral contrasts) in the left superior occipital, postcentral, middle frontal, and superior temporal gyrus, as well as in the left precuneus and cerebellum (Fig. 5; Table 3). In the right hemisphere, there were significant differences in middle, medial, and inferior frontal, precentral, middle temporal, and fusiform gyrus, and the superior parietal lobule. We observed one small cluster in left EBA ( $x=-50, y=-72, z=10,16$ voxels), one small cluster in right EBA ( $x=48, y=-66, z=8,11$ voxels), and one cluster in right pSTS ( $x=56, y=-42, z=4,20$ voxels). The reverse contrast (left resection group vs controls) revealed no significant differences in activation.

Left versus right resection group. Compared with the right resection group, left ATL resection patients show a stronger emotion effect (i.e., a two-sample $t$ test comparing each of the four emotions vs neutral contrasts) in the left calcarine sulcus extending in the left occipital lobe and the precuneus (Fig. 5, violet outline). There were no significant differences in activation in the 
Table 3. Whole-brain fMRI group differences for the emotion effect (i.e., twosample $t$ test on the average of each of the four emotions vs neutral contrasts) ${ }^{a}$

\begin{tabular}{|c|c|c|c|c|c|c|c|}
\hline \multirow[b]{2}{*}{ Region } & \multirow[b]{2}{*}{ Hemisphere } & \multicolumn{3}{|c|}{ Coordinates } & \multirow[b]{2}{*}{$t$} & \multirow{2}{*}{$\begin{array}{l}\text { No. of } \\
\text { voxels }\end{array}$} & \multirow[b]{2}{*}{$p$} \\
\hline & & $x$ & $y$ & $z$ & & & \\
\hline \multicolumn{8}{|c|}{ Controls versus right ATL resection patients } \\
\hline \multirow[t]{2}{*}{ Precun } & $\mathrm{L}$ & -2 & -82 & 46 & 6.32 & 205 & $>0.001$ \\
\hline & $\mathrm{R}$ & 10 & -88 & 40 & 5.15 & & \\
\hline Cingulum & $\mathrm{R}$ & 18 & 0 & 36 & 6.17 & 85 & $>0.001$ \\
\hline LOC & L & -54 & -64 & 2 & 5.95 & 38 & 0.003 \\
\hline Nc & $\mathrm{R}$ & 30 & -30 & 2 & 5.89 & 44 & 0.002 \\
\hline SPL & $\mathrm{R}$ & 22 & -52 & 68 & 5.62 & 20 & 0.007 \\
\hline Precun & $\mathrm{R}$ & 18 & -78 & 54 & 5.61 & 25 & 0.005 \\
\hline MOG & $\mathrm{R}$ & 34 & -74 & 20 & 5.58 & 35 & 0.003 \\
\hline \multirow[t]{2}{*}{ FG } & $\mathrm{R}$ & 48 & -50 & -18 & 5.57 & 126 & $>0.001$ \\
\hline & & 50 & -50 & -26 & 5.48 & & \\
\hline \multirow[t]{2}{*}{ PHG/amygdala } & $\mathrm{R}$ & 26 & 4 & -22 & 5.42 & 44 & 0.002 \\
\hline & & 26 & -2 & -12 & 5.27 & & \\
\hline Precun & $\mathrm{R}$ & 18 & -78 & 54 & 7.85 & 200 & $>0.001$ \\
\hline \multirow[t]{3}{*}{ SOG } & $\mathrm{L}$ & -36 & -86 & 26 & 6.88 & 454 & $>0.001$ \\
\hline & & -48 & -72 & 12 & 6.26 & & \\
\hline & & -54 & -60 & 6 & 6.23 & & \\
\hline MFG & $\mathrm{L}$ & -48 & 32 & 36 & 6.67 & 67 & 0.001 \\
\hline \multirow[t]{2}{*}{ PoCG } & $\mathrm{L}$ & -30 & -34 & 70 & 6.2 & 144 & $>0.001$ \\
\hline & & -42 & -32 & 64 & 5.92 & & \\
\hline \multirow[t]{2}{*}{$\operatorname{PrCG}$} & $\mathrm{R}$ & 26 & 0 & 32 & 6.2 & 187 & $>0.001$ \\
\hline & & 26 & 6 & 26 & 5.79 & & \\
\hline \multicolumn{8}{|c|}{ Controls versus left ATL resection patients } \\
\hline Precun & $\mathrm{L}$ & -16 & -80 & 56 & 6.1 & 38 & 0.003 \\
\hline MeFG & $\mathrm{R}$ & 10 & -8 & 52 & 5.94 & 35 & 0.003 \\
\hline MFG & $\mathrm{R}$ & 54 & 38 & 26 & 5.92 & 81 & $>0.001$ \\
\hline SPL & $\mathrm{R}$ & 20 & -50 & 68 & 5.84 & 24 & 0.006 \\
\hline IFG & $\mathrm{R}$ & 56 & 30 & 10 & 5.67 & 30 & 0.004 \\
\hline Precun & $\mathrm{L}$ & -2 & -84 & 50 & 5.63 & 30 & 0.004 \\
\hline Cereb, pyramis & $\mathrm{L}$ & -12 & -74 & -38 & 5.6 & 32 & 0.004 \\
\hline STG & $\mathrm{L}$ & -62 & -48 & 8 & 5.49 & 20 & 0.007 \\
\hline FG & $\mathrm{R}$ & 44 & -48 & -16 & 5.49 & 36 & 0.003 \\
\hline MTG & $\mathrm{R}$ & 60 & -42 & 0 & 5.39 & 50 & 0.001 \\
\hline \multirow[t]{2}{*}{ LOC } & $\mathrm{R}$ & 40 & -70 & 12 & 5.33 & 40 & 0.002 \\
\hline & & 48 & -66 & 8 & 4.85 & & \\
\hline
\end{tabular}

a Precun, Precuneus; LOC, lateral occipitotemporal cortex; Nc, caudate nucleus; SPL, superior parietal lobule; MOG, middle occipital gyrus; FG, fusiform gyrus; $\mathrm{PHC}$, parahippocampal gyrus.

body-responsive ROIs. The reversed contrast (right vs left resection group) revealed no significant differences.

MVPA: within group results

Control subjects. In the control group, all three ROIs reliably categorized between emotional and neutral stimuli, as was determined by permutation testing with 1000 permutations (right EBA: $t_{(11)}=5.897, p<0.001, d=1.702$; left EBA: $t_{(11)}=3.939$, $p=0.002, d=1.137$; right pSTS: $t_{(11)}=7.966, p<0.001, d=2.3$ ) (Fig. 6). For discriminating between the four emotions separately, the three ROIs performed significantly above chance level as well (right EBA: $t_{(11)}=4.451, p=0.001, d=1.285$; left EBA: $t_{(11)}=5.946, p<0.001, d=1.716$; right pSTS: $t_{(11)}=3.362, p=$ $0.006, d=0.970)$.

Right TLE. In the right resection group, all three ROIs reliably categorize between emotional and neutral stimuli, as was determined by permutation testing with 1000 permutations (right EBA: $t_{(9)}=5.514, p<0.0001, d=1.744$; left EBA: $t_{(9)}=7.856$, $p<0.001, d=2.484$; right pSTS: $t_{(9)}=3.354, p=0.008, d=$ 1.06). For discriminating between the four emotions separately, bilateral EBA ROIs performed significantly above chance level as well (right EBA: $t_{(9)}=3.475, p=0.007, d=1.099$; left EBA: $t_{(9)}=$ 3.926, $p=0.003, d=1.241)$. However, right pSTS does not reliably discriminate between the four emotions in this patient group $\left(t_{(9)}=2.023, p=0.222\right.$, uncorrected $)$.
Left TLE. In the left resection group, both right EBA and rpSTS reliably categorize emotional and neutral stimuli, as was determined by permutation testing with 1000 permutations (right EBA: $t_{(8)}=3.578, p=0.007, d=1 ; 192$; right pSTS: $t_{(8)}=3.5, p=$ $0.008, d=1.167)$. In left EBA categorization, performance between emotional and neutral stimuli did not surpass chance level $\left(t_{(8)}=2.412, p=0.126\right.$, uncorrected). For discriminating between the four emotions, the left EBA performed significantly above chance level $\left(t_{(8)}=4, p=0.004, d=1.333\right)$, unlike the other areas (right EBA: $t_{(8)}=2.997, p=0.051$, uncorrected; right pSTS: $t_{(8)}=2.667, p=0.087$, uncorrected).

\section{MVPA: group differences}

Linear mixed-model analysis on the accuracy minus chance values for the emotions versus neutral categorization showed no effect of group $\left(F_{(2.30)}=1811, p=0.181\right)$ nor $\mathrm{ROI}\left(\mathrm{F}_{(2.37)}=\right.$ $1.632, p=0.209$ ) (Fig. 6). However, the interaction group $\times$ ROI was significant $\left(F_{(4.37)}=4845, p=0.003\right)$. Post hoc tests revealed a significant difference between the healthy controls and the right resection group in the right pSTS only $\left(t_{(29.56)}=3.112, p=0.012\right.$, 95\% CI [3.456, 34.044]).

For the categorization of four emotions, linear mixed-model analysis on the accuracy minus chance values showed no significant effect of group $\left(F_{(2.78)}=0.549, p=0.580\right)$ nor a significant interaction between group and $\operatorname{ROI}\left(F_{(4.63)}=0.155, p=0.960\right)$. The effect of ROI was significant $\left(F_{(2.63)}=6.298, p=0.003\right)$. Post $h o c$ tests revealed a significant difference between left EBA and right pSTS $\left(t_{(53.143)}=3.23, p=0.005,95 \%\right.$ CI $\left.[2.176,15.185]\right)$, with better performance in right STS.

\section{Discussion}

To investigate body emotion processing, we used artificial stimuli expressing emotions conveyed through motion (Sokolov et al., 2011; Krüger et al., 2013).

The first aim was to investigate whether the ATL and the amygdala in particular play a crucial role in the perception of emotional body expressions. The results reveal normal body emotion categorization performance in both patient groups. Hence, our data further challenge a key role for the amygdala in accurate interpretation of emotional body language. This is in line with neuropsychological evidence of preserved body expression recognition in patients with bilateral amygdalar atrophy due to Urbach-Wiethe disease (Atkinson et al., 2007; de Gelder et al., 2014). On the contrary, another syndrome characterized by amygdalar atrophy (i.e., bvFTD) is associated with deficits in recognizing body expressions (Van den Stock, De Winter, et al., 2015; Jastorff et al., 2016). However, those studies also revealed that the deficits were not related to structural integrity of the amygdala, but rather to the volume of a region in the left temporal pole (not overlapping the amygdala) and the left inferior frontal gyrus (Jastorff et al., 2016). Interestingly, we observed in the same sample of bvFTD a facial emotion recognition deficit that was associated with structural integrity of the amygdala (De Winter et al., 2016). These results suggest a dissociation in the structural neuroanatomy underlying body and face emotion recognition deficits. This notion is supported by the finding that the sensitivity of the amygdala is higher to facial than to body emotions (Kret et al., 2011) and suggests that, while the amygdala is necessary to recognize facial expressions, it is not necessary to recognize body expressions. This is in line with a functional hypothesis of the amygdala as a personal relevance detector and modulator of brain processes underlying adaptive behavior (Sander et al., 2003; Janak and Tye, 2015). The amygdala is functionally con- 
nected to primary visual areas but also to motor structures and frontal cortices (Bickart et al., 2012, 2014; Grèzes et al., 2014; Toschi et al., 2017). The disproportional effect of amygdalar lesions on processing facial compared with bodily expressions may thus relate to social stimulus proximity detection and regulating personal space (Kennedy et al., 2009). In particular, detailed perception of a facial expression typically implies closer proximity and hence higher personal relevance compared with perceiving a whole body. Similarly, our findings are in line with studies relating the amygdala to driving eye gaze and attention to the eyes of others (Adolphs et al., 2005; Gamer and Büchel, 2009).

The second aim of the study was to reveal whether amygdala lesions influence neural processes in distant areas, particularly body-sensitive regions.

Both patient groups showed decreased activation in left EBA and right fusiform gyrus. Additionally, the left resection group showed no emotional enhancement in right EBA and pSTS. The right resection group, however, shows an emotional response in the right EBA and STS. These findings support a central role for the amygdala in emotional enhancement of ventral (FBA) but not posterior lateral temporal cortex when perceiving body expressions. This is in line with facial expression recognition findings in patients with amygdalar lesions (Vuilleumier et al., 2004; De Winter et al., 2016) and structural connectivity studies in normal subjects reporting white matter tracts between amygdala and ventral posterior areas, but not STS (Smith et al., 2009; Gschwind et al., 2012).

On the other hand, the MVPA results in the right pSTS reveal a reduction in the right ATL patients in distinguishing emotional from neutral stimuli. This suggests that the ATL and amygdala directly or indirectly influence the function of the pSTS when processing body expressions. Reduced activation in PSTS in response to facial expressions has been observed in patients with ATL lesions (Vuilleumier et al., 2004; Ahs et al., 2014). While there is evidence that amygdala and pSTS are functionally connected (Pitcher et al., 2017; Sato et al., 2017), body emotion processing in posterior lateral temporal cortices, such as EBA and right pSTS, may rely primarily on nonamygdalar input, such as cortical visual areas and motor areas (Ewbank et al., 2011; Lahnakoski et al., 2012; Erickson et al., 2017; Zimmermann et al., 2018). One could speculate that altered input from, for example, FBA, due to absent amygdalar modulation, could explain the reduced emotion classification in the right pSTS.

The effects at distance we observe are not confined to the ipsilateral hemisphere. This is surprising because amygdala modulations have, up until now, been described predominantly ipsi- lateral to the lesion side (Vuilleumier et al., 2004). We speculate that these contralateral altered responses rely on altered input from the homotopic visual areas ipsilateral to the lesion side, which in turn receives diminished input from the lesioned amygdala. There is indeed evidence for corpus callosum deficits in TLE, which results in diminished interhemispheric transfer (Schneider et al., 2014).

Interestingly, we also observed strong distant effects of ATL resections beyond body-responsive visual areas (i.e., in frontal, parietal, occipital, and cingulate regions), which showed emotional enhancement in the control group. Widespread activation during body motion perception (Pavlova et al., 2017) and emotional body expression perception have consistently been reported (de Gelder et al., 2004; de Gelder, 2006; Grèzes et al., 2007; Pichon et al., 2008; van de Riet et al., 2009; Kret et al., 2011). The present results suggest that these activations may also be primarily amygdala-dependent. 
The notion that specific emotions can be mapped to specific brain circuits has been increasingly challenged by psychological constructionist theories. These models hypothesize that processing of emotions relies on distributed brain networks and processing of specific emotions relies on coactivation patterns within and between those networks (Lindquist et al., 2012; Barrett, 2013; Jastorff et al., 2015; Huang et al., 2018). The amygdala is considered a "core affect" region in constructionist accounts, adding to the representation of emotional events in concert with other areas and networks. Indeed, the amygdala is strongly connected to other regions of the social brain. It is considered to be involved in multiple processes with a common ground of detecting arousal and salience in multiple types of stimuli (i.e., emotional, novel, rewarding stimuli) (Sander et al., 2003; Adolphs, 2010). As a "relevance detector," it seems to modulate several of these social brain regions to facilitate adaptive behavior (Bickart et al., 2014). There is indeed evidence that the amygdala is both structurally and functionally linked to (pre)motor areas, such as the supplementary motor area and precentral and postcentral gyri (Pichon et al., 2008; Grèzes et al., 2014; Toschi et al., 2017).

Several limitations of the present study need to be addressed. The normal performance of body emotion recognition in the clinical groups may be related to insufficient sensitivity of our behavioral task, although the sensitivity of psychometric function modeling may surpass conventional accuracy measures (Biotti and Cook, 2016). Second, TLE is associated with ATL sclerosis and deficits in emotion recognition (Monti and Meletti, 2015), also before surgery. As we did not include presurgical data nor patients with active temporal lobe epilepsy, we cannot conclude that the group differences are due to the resection of the ATL.

A related issue to consider is the neural plasticity that may have taken place after the resection but also before, possibly compensating for the amygdala and ATL. While functional compensation may occur in contralateral amygdala, we did not find any evidence for increased responses to emotional stimuli in patients compared with healthy controls. Furthermore, in neither patient group did we observe an emotion effect in the intact amygdala, suggesting no compensatory activation from contralateral amygdala.

There is evidence that emotion recognition in TLE depends on intellectual capacity (Monti and Meletti, 2015), and we excluded patients with total IQ $<80$. While this exclusion criterion benefits the validity of comparisons with the control group, it may also reduce the sensitivity to reveal IQdependent behavioral effects.

Our sample size is rather small and may negatively influence statistical power. To compensate for this, we applied a conservative statistical threshold (FWE correction) to maximize the reliability of the significance of the group differences. It should, however, be noted that this stringent control for Type I errors increases the probability of Type II errors, which we considered less relevant for the present study purpose.

Finally, antiepileptic medication in a part of the patient group, while absent in the control group, might also have influenced the results.

In conclusion, the findings reveal that unilateral ATL resection does not reduce recognition of body emotions despite the indications that it plays a central role in enhancing activation in the right fusiform gyrus during body emotion perception. Furthermore, the enhanced activity in a widely distributed set of regions during body emotion perception supports the role of the amygdala as a hub in the emotional brain.

\section{References}

Adolphs R (2010) What does the amygdala contribute to social cognition? Ann N Y Acad Sci 1191:42-61. CrossRef Medline

Adolphs R, Tranel D, Damasio H, Damasio A (1994) Impaired recognition of emotion in facial expressions following bilateral damage to the human amygdala. Nature 372:669-672. CrossRef Medline

Adolphs R, Tranel D, Hamann S, Young AW, Calder AJ, Phelps EA, Anderson A, Lee GP, Damasio AR (1999) Recognition of facial emotion in nine individuals with bilateral amygdala damage. Neuropsychologia 37:11111117. CrossRef Medline

Adolphs R, Gosselin F, Buchanan TW, Tranel D, Schyns P, Damasio AR (2005) A mechanism for impaired fear recognition after amygdala damage. Nature 433:68-72. CrossRef Medline

Ahs F, Engman J, Persson J, Larsson EM, Wikström J, Kumlien E, Fredrikson M (2014) Medial temporal lobe resection attenuates superior temporal sulcus response to faces. Neuropsychologia 61:291-298. CrossRef Medline

Atkinson AP, Heberlein AS, Adolphs R (2007) Spared ability to recognise fear from static and moving whole-body cues following bilateral amygdala damage. Neuropsychologia 45:2772-2782. CrossRef Medline

Barrett LF (2013) Psychological construction: a darwinian approach to the science of emotion. Emotion Rev 5:379-389. CrossRef

Bickart KC, Hollenbeck MC, Barrett LF, Dickerson BC (2012) Intrinsic amygdala-cortical functional connectivity predicts social network size in humans. J Neurosci 32:14729-14741. CrossRef Medline

Bickart KC, Dickerson BC, Barrett LF (2014) The amygdala as a hub in brain networks that support social life. Neuropsychologia 63:235-248. CrossRef Medline

Brainard DH (1997) The psychophysics toolbox. Spat Vis 10:433-436. CrossRef Medline

Biotti F, Cook R (2016) Impaired perception of facial emotion in developmental prosopagnosia. Cortex, 81, 126-136.

Brett M, Anton JL, Valabregue R, Poline JB (2002) Region of interest analysis using an SPM toolbox. 8th International Conference on Functional Mapping of the Human Brain, Sendai, Japan.

Dale AM (1999) Optimal experimental design for event-related fMRI. Hum Brain Mapp 8:109-114. CrossRef Medline

de Gelder B (2006) Towards the neurobiology of emotional body language. Nat Rev Neurosci 7:242-249. CrossRef Medline

de Gelder B, Snyder J, Greve D, Gerard G, Hadjikhani N (2004) Fear fosters flight: a mechanism for fear contagion when perceiving emotion expressed by a whole body. Proc Natl Acad Sci U S A 101:16701-16706. CrossRef Medline

de Gelder B, Terburg D, Morgan B, Hortensius R, Stein DJ, van Honk J (2014) The role of human basolateral amygdala in ambiguous social threat perception. Cortex 52:28-34. CrossRef Medline

De Winter FL, Van den Stock J, de Gelder B, Peeters R, Jastorff J, Sunaert S, Vanduffel W, Vandenberghe R,Vandenbulcke M (2016) Amygdala atrophy affects emotion-related activity in face-responsive regions in frontotemporal degeneration. Cortex 82:179-191. CrossRef Medline

Diano M, Tamietto M, Celeghin A, Weiskrantz L, Tatu MK, Bagnis A, Vanduffel W, Vandenberghe R,Costa T (2017) Dynamic changes in amygdala psychophysiological connectivity reveal distinct neural networks for facial expressions of basic emotions. Sci Rep 7:45260. CrossRef Medline

Erickson LC, Rauschecker JP, Turkeltaub PE (2017) Meta-analytic connectivity modeling of the human superior temporal sulcus. Brain Struct Funct 222:267-285. CrossRef Medline

Ewbank MP, Lawson RP, Henson RN, Rowe JB, Passamonti L, Calder AJ (2011) Changes in "top-down" connectivity underlie repetition suppression in the ventral visual pathway. J Neurosci 31:5635-5642. CrossRef Medline

Fusar-Poli P, Placentino A, Carletti F, Landi P, Allen P, Surguladze S, Benedetti F, Abbamonte M, Gasparotti R, Barale F, Perez J, McGuire P, Politi P (2009) Functional atlas of emotional faces processing: a voxel-based meta-analysis of 105 functional magnetic resonance imaging studies. J Psychiatry Neurosci 34:418-432. Medline

Gamer M, Büchel C (2009) Amygdala activation predicts gaze toward fearful eyes. J Neurosci 29:9123-9126. CrossRef Medline

Giese MA, Poggio T (2000) Morphable models for the analysis and synthesis of complex motion pattern. Int J Comput Vis 38:59-73.

Goldberg H, Christensen A, Flash T, Giese MA, Malach R (2015) Brain ac- 
tivity correlates with emotional perception induced by dynamic avatars. Neuroimage 122:306-317. CrossRef Medline

Grèzes J, Pichon S, de Gelder B (2007) Perceiving fear in dynamic body expressions. Neuroimage 35:959-967. CrossRef Medline

Grèzes J, Valabregue R, Gholipour B, Chevallier C (2014) A direct amygdala-motor pathway for emotional displays to influence action: a diffusion tensor imaging study. Hum Brain Mapp 35:5974-5983. CrossRef Medline

Gschwind M, Pourtois G, Schwartz S, Van De Ville D, Vuilleumier P (2012) White-matter connectivity between face-responsive regions in the human brain. Cereb Cortex 22:1564-1576. CrossRef Medline

Hadjikhani N, de Gelder B (2003) Seeing fearful body expressions activates the fusiform cortex and amygdala. Curr Biol 13:2201-2205. CrossRef Medline

Haxby JV, Gobbini MI (2011) Distributed neural systems for face perception. In: The Oxford handbook of face perception (Calder AJ, Rhodes G, Johnson M, eds), pp 93-110. New York: Oxford UP.

Hebart MN, Görgen K, Haynes JD (2014) The Decoding Toolbox (TDT): a versatile software package for multivariate analyses of functional imaging data. Front Neuroinform 8:88. CrossRef Medline

Herrington JD, Taylor JM, Grupe DW, Curby KM, Schultz RT (2011) Bidirectional communication between amygdala and fusiform gyrus during facial recognition. Neuroimage 56:2348-2355. CrossRef Medline

Huang YA, Jastorff J, Van den Stock J, Van de Vliet L, Dupont P, Vandenbulcke M (2018) Studying emotion theories through connectivity analysis: evidence from generalized psychophysiological interactions and graph theory. Neuroimage 172:250-262. CrossRef Medline

Janak PH, Tye KM (2015) From circuits to behaviour in the amygdala. Nature 517:284-292. CrossRef Medline

Jastorff J, De Winter FL, Van den Stock J, Vandenberghe R, Giese MA, Vandenbulcke M (2016) Functional dissociation between anterior temporal lobe and inferior frontal gyrus in the processing of dynamic body expressions: insights from behavioral variant frontotemporal dementia. Hum Brain Mapp 37:4472-4486. CrossRef Medline

Jastorff J, Huang YA, Giese MA, Vandenbulcke M (2015) Common neural correlates of emotion perception in humans. Hum Brain Mapp 36:41844201. CrossRef Medline

Jastorff J, Kourtzi Z, Giese MA (2006) Learning to discriminate complex movements: Biological versus artificial trajectories. J Vis 6:791-804.

Kennedy DP, Gläscher J, Tyszka JM, Adolphs R (2009) Personal space regulation by the human amygdala. Nat Neurosci 12:1226-1227. CrossRef Medline

Kret ME, Pichon S, Grèzes J, de Gelder B (2011) Similarities and differences in perceiving threat from dynamic faces and bodies. an fMRI study. Neuroimage 54:1755-1762. CrossRef Medline

Krüger S, Sokolov AN, Enck P, Krägeloh-Mann I, Pavlova MA (2013) Emotion through locomotion: gender impact. PLoS One 8:e81716. CrossRef Medline

Kumfor F, Hazelton JL, De Winter, FL de Langavant LC, Van den Stock, J (2017) Clinical Studies of Social Neuroscience: A Lesion Model Approach. In A Ibáñez, L Sedeño, \& A M García (Eds.), Neuroscience and Social Science: The Missing Link (pp. 255-296). Cham: Springer International Publishing.

Lahnakoski JM, Glerean E, Salmi J, Jääskelainen IP, Sams M, Hari R, Nummenmaa L (2012) Naturalistic FMRI mapping reveals superior temporal sulcus as the hub for the distributed brain network for social perception. Front Hum Neurosci 6:233. CrossRef Medline

Lindquist KA, Wager TD, Kober H, Bliss-Moreau E, Barrett LF (2012) The brain basis of emotion: a meta-analytic review. Behav Brain Sci 35:121143. CrossRef Medline

Monti G, Meletti S (2015) Emotion recognition in temporal lobe epilepsy: a systematic review. Neurosci Biobehav Rev 55:280-293. CrossRef Medline

Morris JS, Frith CD, Perrett DI, Rowland D, Young AW, Calder AJ, Dolan RJ (1996) A differential neural response in the human amygdala to fearful and happy facial expressions. Nature 383:812-815. CrossRef Medline

Morris JS, Friston KJ, Büchel C, Frith CD, Young AW, Calder AJ, Dolan RJ (1998) A neuromodulatory role for the human amygdala in processing emotional facial expressions. Brain 121:47-57. CrossRef Medline

Olson IR, Plotzker A, Ezzyat Y (2007) The Enigmatic temporal pole: a review of findings on social and emotional processing. Brain 130:17181731. CrossRef Medline
Pavlova MA, Erb M, Hagberg GE, Loureiro J, Sokolov AN, Scheffler K (2017) 'Wrong way up': temporal and spatial dynamics of the networks for body motion processing at 9.4 T. Cereb Cortex 27:5318-5330. CrossRef Medline

Peelen MV, Downing PE (2005) Selectivity for the human body in the fusiform gyrus. J Neurophysiol 93:603-608. CrossRef Medline

Peelen MV, Atkinson AP, Andersson F, Vuilleumier P (2007) Emotional modulation of body-selective visual areas. Soc Cogn Affect Neurosci 2:274-283. CrossRef Medline

Peelen MV, Atkinson AP, Vuilleumier P (2010) Supramodal representations of perceived emotions in the human brain. J Neurosci 30:1012710134. CrossRef Medline

Pichon S, de Gelder B, Grèzes J (2008) Emotional modulation of visual and motor areas by dynamic body expressions of anger. Soc Neurosci 3:199212. CrossRef Medline

Pitcher D, Japee S, Rauth L, Ungerleider LG (2017) The superior temporal sulcus is causally connected to the amygdala: a combined TBS-fMRI study. J Neurosci 37:1156-1161. CrossRef Medline

Ripollés P, Marco-Pallarés J, de Diego-Balaguer R, Miró J, Falip M, Juncadella M, Rubio F, Rodriguez-Fornells A (2012) Analysis of automated methods for spatial normalization of lesioned brains. Neuroimage 60:12961306. CrossRef Medline

Roether CL, Omlor L, Christensen A, Giese MA (2009) Critical features for the perception of emotion from gait. J Vis 9:15 1-32. CrossRef Medline

Rosen HJ, Perry RJ, Murphy J, Kramer JH, Mychack P, Schuff N, Weiner M, Levenson RW, Miller BL (2002) Emotion comprehension in the temporal variant of frontotemporal dementia. Brain 125:2286-2295. CrossRef Medline

Sander D, Grafman J, Zalla T (2003) The human amygdala: an evolved system for relevance detection. Rev Neurosci 14:303-316. Medline

Sato W, Kochiyama T, Uono S, Yoshikawa S, Toichi M (2017) Direction of amygdala-neocortex interaction during dynamic facial expression processing. Cereb Cortex 27:1878-1890. CrossRef Medline

Schneider C, Helmstaedter C, Luders E, Thompson PM, Toga AW, Elger C, Weber B (2014) Relation of callosal structure to cognitive abilities in temporal lobe epilepsy. Front Neurol 5:16. CrossRef Medline

Skerry AE, Saxe R (2014) A common neural code for perceived and inferred emotion. J Neurosci 34:15997-16008. CrossRef Medline

Smith CD, Lori NF, Akbudak E, Sorar E, Gultepe E, Shimony JS, McKinstry RC,Conturo TE (2009) MRI diffusion tensor tracking of a new amygdalofusiform and hippocampo-fusiform pathway system in humans. J Magn Reson Imaging 29:1248-1261. CrossRef Medline

Sokolov AA, Krüger S, Enck P, Krägeloh-Mann I, Pavlova MA (2011) Gender affects body language reading. Front Psychol 2:16. CrossRef Medline

Toschi N, Duggento A, Passamonti L (2017) Functional connectivity in amygdalar-sensory/(pre)motor networks at rest: new evidence from the human connectome project. Eur J Neurosci 45:1224-1229. CrossRef Medline

van de Riet WA, Grèzes J, de Gelder B (2009) Specific and common brain regions involved in the perception of faces and bodies and the representation of their emotional expressions. Soc Neurosci 4:101-120. CrossRef Medline

Van den Stock J (2018) Interaction between identity and emotion versus visual basic object recognition deficits: a commentary on Biotti and Cook. Cortex 101:294-297. CrossRef Medline

Van den Stock J, De Winter FL, de Gelder B, Rangarajan JR, Cypers G, Maes F, Sunaert S, Goffin K, Vandenberghe R, Vandenbulcke M (2015) Impaired recognition of body expressions in the behavioral variant of frontotemporal dementia. Neuropsychologia 75:496-504. CrossRef Medline

Van den Stock J, Hortensius R, Sinke C, Goebel R, de Gelder B (2015) Personality traits predict brain activation and connectivity when witnessing a violent conflict. Sci Rep 5:13779. CrossRef Medline

Vuilleumier P, Richardson MP, Armony JL, Driver J, Dolan RJ (2004) Distant influences of amygdala lesion on visual cortical activation during emotional face processing. Nat Neurosci 7:1271-1278. CrossRef Medline

Vuilleumier P, Pourtois G (2007) Distributed and interactive brain mechanisms during emotion face perception: evidence from functional neuroimaging. Neuropsychologia 45:174-194. CrossRef Medline

Zimmermann M, Mars RB, de Lange FP, Toni I, Verhagen L (2018) Is the extrastriate body area part of the dorsal visuomotor stream? Brain Struct Funct 223:31-46. CrossRef Medline 